\title{
Analysis of the Design and Engineering-Process towards a First Prototype in the Field of Sports and Vitality ${ }^{\dagger}$
}

\author{
Mark Janssen 1,2, , Roy van den Heuvel ${ }^{2}$, Carl Megens ${ }^{2}$, Pierre Levy ${ }^{2}$ and Steven Vos ${ }^{1,2}$ \\ 1 School of Sport Studies, Fontys University of Applied Sciences, 5644HZ Eindhoven, The Netherlands; \\ s.vos@fontys.nl \\ 2 Industrial Design, Eindhoven University of Technology, 5600MB Eindhoven, The Netherlands; \\ R.v.d.Heuvel@tue.nl (R.v.d.H.); c.megens@fontys.nl (C.M.); p.d.levy@tue.nl (P.L.) \\ * Correspondence: mark.janssen@fontys.nl; Tel.: +31-63-052-8416 \\ + Presented at the 12th Conference of the International Sports Engineering Association, Brisbane, \\ Queensland, Australia, 26-29 March 2018.
}

Published: 22 February 2018

\begin{abstract}
The scope of technology has expanded towards areas such as sports and vitality, offering significant challenges for engineering designers. However, only little is known about the underlying design and engineering processes used within these fields. Therefore, this paper aims to get an indepth understanding of these type of processes. During a three-day design competition (Hackathon), three groups of engineers were challenged to develop experience-able prototypes in the field of sports and vitality. Their process was monitored based on the Reflective Transformative Design process (RTD-process) framework, describing the various activities part of the design process. Groups had to keep track of their activities, and six group reflection-sessions were held. Results show that all groups used an open and explorative approach, they frequently swapped between activities, making them able to reflect on their actions. While spending more time on envisioning and creating a clear vision seem to relate to the quality of the design concept.
\end{abstract}

Keywords: prototype; design process; engineering process; sport and vitality; hackathon

\section{Introduction}

The scope of engineering design has expanded towards areas like sports, physical activity and vitality. There are several arguments for this. First, there is a growing awareness to tackle physical inactivity and sedentary behaviour, which is a major public health concern [1]. Second, there is an increasing attention for healthy lifestyles and vitality. Nowadays, people can choose their own way of being involved in sports, compatible with their own individual lifestyle and consistent with their own interests [2]. When incorporating these characteristics, sports can play a determined role towards vitality and contribute to a healthier lifestyle. Third, recent developments in low-cost sensor technologies have opened new markets and possibilities [3]. Fourth, the sports participation sector has become a significant economic sector [4]. For example, in recent years there has been an exponential increase in the availability and use of sports and physical activity-related monitoring devices [5,6].

It is obvious that technology creates new opportunities for the field of sports and vitality, but also offers significant challenges for engineering designers. For instance, Wilson and colleague's [7] found that in general product design multiple iterations were used within and between different design phases, in the sports product design only iterations within each design phases were used, and rarely between design phases. Thereby, the design space in this field is enormous, and requires a distinctive approach and envisioning of societal and personal needs. Amongst others, the target 
group is extremely heterogeneous in terms of physical abilities, training load responses, motivational drivers and attitudes [3,5], and it aims to create behaviour changes in patterns that are deeply rooted in daily life [8]. Therefore, this paper aims to unravel these processes used by future engineering designers towards a first prototype in the field of sports and vitality.

\section{Reflective Transformative Design Process}

The Reflective Transformative Design process framework (RTDP), introduced by Hummels and Frens [9] is an open framework for designing, but can also be used as a framework to describe and analyse design processes. Its structure, by nature open and flexible, based on activities and the links between them, provides an open yet structured way to analyse any design process. The RTDP is: " $a$ design process, particularly aimed to support the design of disruptive innovative and/or intelligent systems, products, and services" [9] (p. 147). The model consists of five circles (Figure 1). The middle circle 'decisions' can be seen as a process of making decisions based on information of the other four circles. The remaining four circles can be seen as strategies to generate or gather information. 'Envisioning' is information gathering to create a designer's vision. It is used to give direction to the design process. Like every circle, in the beginning, this vision is small, based on little information and must develop during the process. Exploring $\mathcal{E}$ validating is used to gather information by validating the design decisions through experience-able prototypes. For example, testing a concept by experts, or validating a simple prototype in real life. The circle of thinking consists of analyzing and abstracting to create a framework or model. Making is the last strategy, creating experience-able prototypes and producing experiential information. Hummels and Frens [9] stated that "Design making enables the designer to use her intuition and through making the designer can open up new solution spaces that go beyond imagination" [9] (p. 161). Given the connections and relatedness between all circles and activities, it is recommended to swap frequently from one to the other circle. Through swapping, engineers are forced to incorporating different kinds of information to feed the design decisions. This enables the engineers to reflect on the activities in and during action. In this paper, we analyse the design and research processes of future design engineers towards vitality and sports focused prototypes through the RTDP model.

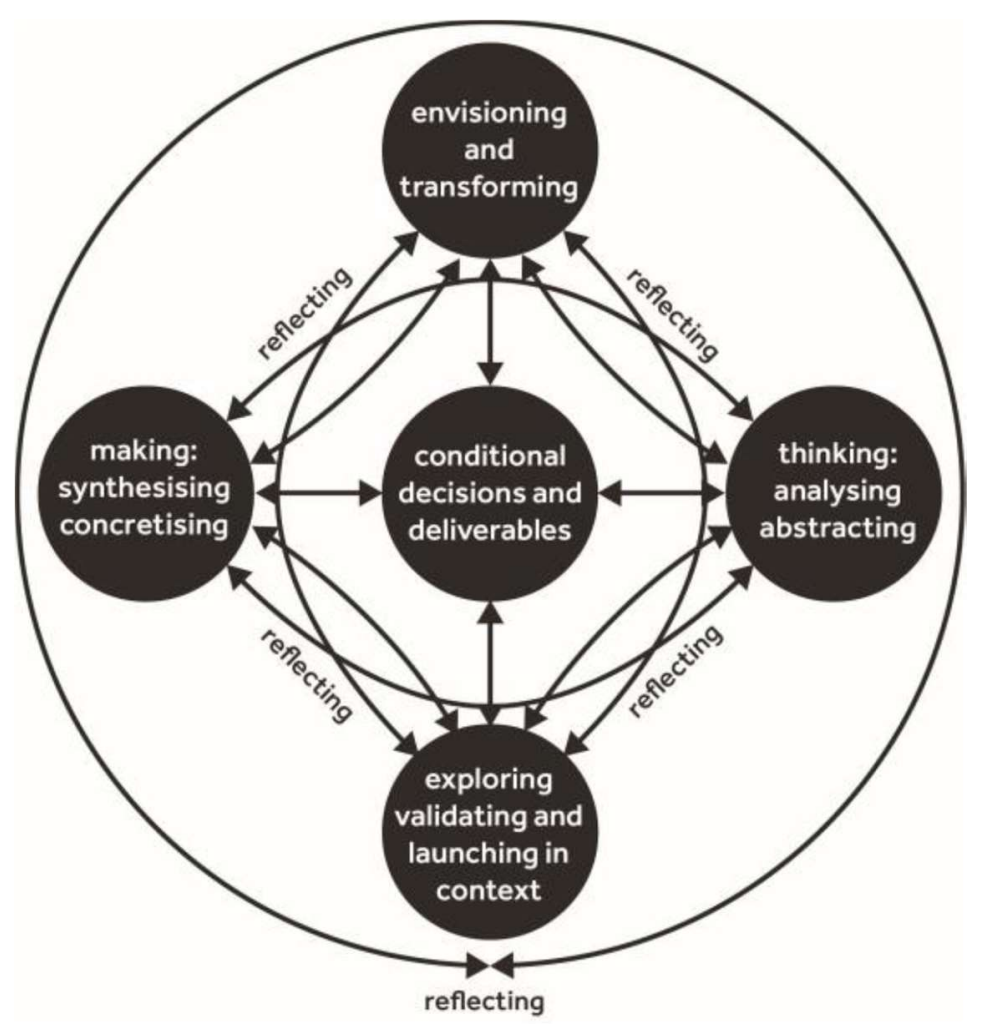

Figure 1. the Reflective Transformative Design Process [9]. 


\section{Materials and Methods}

\subsection{Hackathon Design Challenge}

During a three-day Hackathon, three groups of future engineering designers $(\mathrm{n}=14)$ were challenged to rapidly prototype practical ideas. The focus was to design for sports and vitality, with specific attention to health-related aspects such as increasing (sports) active behaviour, reducing sedentary behaviour, and reducing stress. Participants joined a topic that interested them. The outcome of hackathon should be a pitch of their concept to the audience and jury, including a working prototype. The research conducted was in line with the ethical principles of the Declaration of Helsinki and the Departmental Research Board. The privacy of all participants was guaranteed, and all data was anonymized before analysis.

\subsection{Procedure}

An interactive, qualitative study design was chosen for this study. A protocol of the RTDP framework [9] was used to map the engineering design process. Each group had the responsibility to keep track of all activities conducted. Sticky notes in different colours (representing different members) were used to write down information of each activity and placed on an overview cardboard. For each activity, the following questions were answered: (i) what was the activity done; (ii) how was the activity performed; (iii) did group members worked alone or with others; and (iv) at what time they started and what was the duration of the activity. Next, a minimum of six short sessions (10 min) on fixed moments (11 am and $6 \mathrm{pm}$, each day) were conducted. These moments stimulated reflection on their activities, but also gave the moderator the opportunity to validate the information on the sticky-notes with the participants.

\subsection{Measurements and Analysis}

The following measurements of the design process were calculated based on the information on the sticky-notes: total number of activities, total time spent on the activity, average time per activity, percentage of the number of activities per strategy and percentage of the time spent per strategy. Next to the process, also the outcome of the hackathon was measured. Seven experts formed a jury and had to score, via a multi-item list, the pitches and the prototypes. Each jury member was forced to rank the groups. In this paper, the rankings of the jury members were summed. If a jury member ranked the group first, 1 point was given. Second place agreed with 2 points, and last place 3 points. The group with the least points won the competition. Spearman's Rho was used to correlate the design process measurements to the jury scores.

\section{Results}

\subsection{Design Process}

First, some general results are described. Next, we will focus on differences between the groups (for an overview see Table 1). Results reveal differences, between groups and group members, in the total time spent on the concepts. For instance, some participants spent around $2000 \mathrm{~min}$, while others spent only $1155 \mathrm{~min}$. Also, the contribution of four information gathering/generating strategies is not equally distributed. The future engineering designers spent only between $3.6 \%$ and $7.6 \%$ of their time on envisioning. Moreover, this approach is mostly used on the first day, and rarely during the second and final day. While information generating by making is by far the most used strategy, every group spent the most of their time (between $54.5 \%$ and $61.2 \%$ ) on activities related to making. Analyses also show differences between groups, group 1 and group 3 did spend about the same total time (4125 min and $4155 \mathrm{~min}$ ), where group 2 spent only $3210 \mathrm{~min}$. Thereby the analyses show that group 1 and 3 followed a similar pattern, spending the least time on envisioning, followed by thinking and exploring $\mathcal{E}$ validating. They spend the most time on making. Group 2 also spent the least time on envisioning but did a lot more thinking compared to the other groups, and less exploring $\mathcal{E}$ validating. Group 3 spent 
$7.6 \%$ of their total time on envisioning ( $315 \mathrm{~min})$. Groups 1 and 2 spent half the time (150 $\mathrm{min}$ ) and only $3.6 \%$ and $4.7 \%$ of the total time on envisioning. All groups swapped between strategies, only the strategy of envisioning (and to some extent thinking) was not incorporated, resulting in alternated use of activities only related to exploring $\mathcal{E}$ validating and making, instead of using all four strategies frequently and alternated.

Table 1. Overview of all measurements of the design process for the different groups (G1, G2, G3).

\begin{tabular}{|c|c|c|c|c|c|c|c|c|c|c|c|c|c|c|c|}
\hline \multirow[b]{2}{*}{ Group } & \multicolumn{3}{|c|}{$\begin{array}{l}\text { Number of } \\
\text { Activities }\end{array}$} & \multicolumn{3}{|c|}{$\begin{array}{c}\text { Total Time (Minutes) } \\
\text { of Activities }\end{array}$} & \multicolumn{3}{|c|}{$\begin{array}{c}\text { Average Time } \\
\text { (Minutes) Per } \\
\text { Activity } \\
\end{array}$} & \multicolumn{3}{|c|}{$\begin{array}{l}\text { Percentage (\%) of Total } \\
\text { Number of Activities } \\
\text { on Activity }\end{array}$} & \multicolumn{3}{|c|}{$\begin{array}{c}\text { Percentage (\%) of } \\
\text { Total Time Spent } \\
\text { on Activity }\end{array}$} \\
\hline & 1 & 2 & 3 & 1 & 2 & 3 & 1 & 2 & 3 & 1 & 2 & 3 & 1 & 2 & 3 \\
\hline Envisioning & 2 & 3 & 3 & 150 & 150 & 315 & 75 & 50 & 105 & 3 & 9 & 7 & 4 & 5 & 8 \\
\hline Thinking & 14 & 7 & 7 & 660 & 780 & 615 & 47 & 111 & 88 & 23 & 21 & 17 & 16 & 24 & 15 \\
\hline $\begin{array}{c}\text { Exploring \& } \\
\text { Validating }\end{array}$ & 19 & 6 & 14 & 975 & 315 & 960 & 51 & 53 & 69 & 31 & 18 & 34 & 24 & 10 & 23 \\
\hline Making & 26 & 18 & 17 & 2340 & 1965 & 2265 & 90 & 109 & 133 & 43 & 53 & 42 & 57 & 61 & 55 \\
\hline Total & 61 & 34 & 41 & 4125 & 3210 & 4155 & 66 & 94 & 101 & 100 & 100 & 100 & 100 & 100 & 100 \\
\hline
\end{tabular}

\subsection{Outcome Hackathon: Concepts}

The first group designed 'Ambi', a system in the form of a Tamagotchi that warns when you are too long inactive or when the air quality decreases. The second group developed 'Freshlook' a system with a stress ball that stimulates you to go for a walk when you sit too long. The third group choose to design a system that detected positive and negative changes in an office environment. These changes were made visible by ripples in the water. This concept was combined with 'AMP' a workshop that should make participants aware of the risks of stress via an interactive puppet.

\subsection{Outcome Hackathon: Jury Scores}

Based on the rankings of the seven jury members. Group 3 won this hackathon based on their concept 'AMP' (9 points). The jury praised this concept because it provides an actual solution for a societal problem and was realistic in terms of practical feasibility. Group 2 (15 points) and Group 1 (18 points) completed the ranking.

\subsection{Relation: Design Process and Outcome}

To relate the measurements of the design process to the jury ranking, correlations (Spearman's Rho) were executed. The number of different activities, as well as total time spent on the concepts, seems not related to the jury ranking. Secondly, average time spent per activity did correlate to jury ranking, the longer the time spent per activity, the higher the ranking of the jury. Group 3 spent almost twice the time on envisioning compared to groups 1 and 2, using a higher percentage of the total time on creating a vision and scope of the concept. Thereby they compensated this time in the making-related activities and came up with a relatively simple, working $3 \mathrm{~d}$ model. Ranked correlations showed that spending more time on envisioning did relate to a better ranking. While spending more or less time on the other strategies did not relate to a better ranking.

\section{Discussion}

This paper focused on unravelling the design process used by future engineering designers towards a first prototype in the field of sports and vitality. It seems that the winning concept not only spent more time on envisioning, but also envisioned more thoroughly. Resulting in a concept that provides an actual solution for a societal problem and is realistic in terms of practical feasibility. In the field of sports and vitality the design space is enormous, requiring a distinctive approach. Hence, the envisioning of societal and personal needs is key. Therefore, spending more time on envisioning and understanding societal and personal needs more thoroughly may have resulted in a better concept. A possible reason why group 3 (master students only) did a more thoroughly envisioning could be related to their prior experience with the RTDP and user-involvement. A limitation of this study is that we included both bachelor and master students. The concepts of the groups were mainly 
focused on vitality related topics. This is a general trend in the Netherlands where recreational sports are more and more connected to being active and living healthy, including issues like sedentary behaviour, stress, burn-out, etc.

Vos et al. [3] stated that to understand the societal and personal needs and, the associated crossovers between different professions require a multidisciplinary approach. This is key for the design and provision of products and services targeting mass sports participation. Since the groups were unidisciplinary, these crossovers did not happen and therefore possibly there was even more to gain in terms of envisioning.

Analyses showed that groups did swap between strategies, only the strategy of envisioning and thinking were rarely incorporated. In line with Wilson and colleagues [7], we also found that groups rarely iterated between different phases in the design process, for example none of the groups did go back to envisioning (including their design brief or design rationale) after the first full day of designing (e.g., Figure 2).

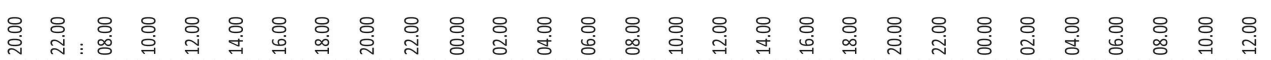

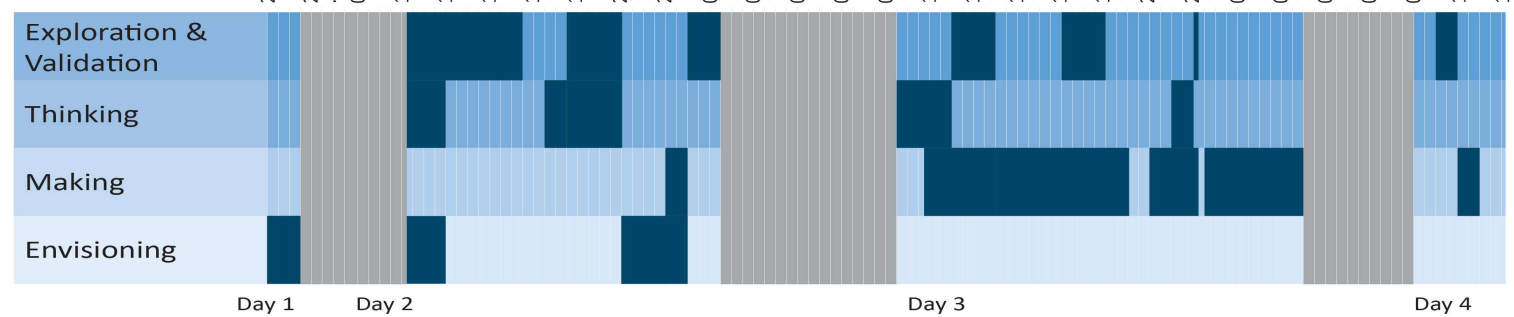

Figure 2. Visualisation of the design process including different strategies, activities and time per activity of group 3 during the three-day Hackathon.

In future research, it can be interesting to monitor the actual methodology the groups used to gather or generate information within the four circle of the RTDP. This will provide not only insight into the quantity of the activities but also the quality. In addition, also the decisions can be monitored to get more insight into which information is used and is decisive. Finally, in future research the design and engineering processes should be monitored over longer periods of time, taking away the time-pressure of the hackathon and to see if there will be changes in quantity and quality of envisioning. Forming multidisciplinary with different expertise can be interesting to facilitate crossovers during the envisioning.

\section{Conclusions}

Technology has created new opportunities for the field of sports and vitality, but also offers significant challenges like the enormous design space in this field and a distinctive approach and envisioning of societal and personal needs for engineering designers [3,5]. This study functioned as a first exploration and has given an insight into how engineering designers use design methods within the field of sports and vitality. It seems that time spent on envisioning, but also envisioning more thoroughly affected the outcome. This finding provides an interesting starting point to further investigate engineering design in the field of sports and vitality.

Acknowledgments: This work was supported by the Netherlands Organisation for Scientific Research (Grant 023.007.056). We would like to thank HC Oranje-Rood for hosting the hackathon and the participants for their contribution during the hackathon.

Conflicts of Interest: The authors declare no conflict of interest. The funding sponsors had no role in the design of the study; in the collection, analyses, or interpretation of data; in the writing of the manuscript, and in the decision to publish the results. 


\section{References}

1. Blair, S.N. Physical inactivity: The biggest public health problem of the 21st century. Br. J. Sports Med. 2009, $43,1-2$

2. Scheerder, J.; Vos, S. Social stratification in adults' sports participation from a time-trend perspective: Results from a 40-year household study. Eur. J. Sport Soc. 2011, 8, 31-44.

3. Vos, S.; Janssen, M.; Goudsmit, J.; Lauwerijssen, C.; Brombacher, A. From problem to solution: A three-step approach to design a personalized smartphone application for recreational runners. Procedia Eng. ISEA 2016, 147, 799-805.

4. Thibaut, E.; Eakins, J.; Vos, S.; Scheerder, J. Time and money expenditure in sports participation: The role of income in consuming the most practiced sports activities in Flanders. Sport Manag. Rev. 2016, doi:10.1016/j.smr.2016.12.002.

5. Janssen, M.; Scheerder, J.; Thibaut, E.; Brombacher, A.; Vos, S. Who uses running apps and sports watches? Determinants and consumer profiles of event runners' usage of running-related smartphone applications and sports watches. PLoS ONE 2017, 12, e0181167, doi:10.1371/journal.pone.0181167.

6. Middelweerd, A.; Mollee, J.S.; van der Wal, C.; Brug, J.; te Velde, S.J. Apps to promote physical activity among adults: A review and content analysis. Int. J. Behav. Nutr. Phys. Act. 2014, 11, doi:10.1186/s12966-0140097-9.

7. Wilson, N. Can the Sports Design Process Help the Inclusive Design Community? In Proceedings of the 20th International Conference on Engineering Design (ICED 15), Design for Life, Milan, Italy, 27-30 July 2015; Volume 1, pp. 1-10.

8. Peeters, R.; Megens, C.J.P.G. Experiential design landscapes : How to design for behaviour change, towards an active lifestyle. Ph.D. Thesis, University of Technology, Eindhoven, The Netherlands, 2014.

9. Hummels, C.; Frens, J.F. Designing Disruptive Innovative Systems, Products and Services: RTD Process. In Industrial Design-New Frontiers; InTech: Rijeka, Croatia, 2011; p. 190.

(C) 2018 by the authors. Licensee MDPI, Basel, Switzerland. This article is an open access article distributed under the terms and conditions of the Creative Commons Attribution (CC BY) license (http://creativecommons.org/licenses/by/4.0/). 